\title{
VARIACIÓN DE LA CONDUCTIVIDAD HIDRAÚLICA SATURADA DE ARENAS CON EL CONTENIDO DE FINOS LIMOSOS
}

\author{
Variation of the saturated hydraulic conductivity \\ of sands with the fine silt content
}

EPISTEMUS

ISSN: 2007-8196 (electrónico)

ISSN: 2007-4530 (impresa)

José Alfredo Espinoza Meléndrez 1

Virgilio Rubio Nieblas 2

Alfredo Francisco Espinoza Mézquita 3

Recibido: 27 de febrero de 2015 ,

Aceptado: 03 de febrero de 2016

Autor de Correspondencia:

Dr. Virgilio Rubio Nieblas

Correo: virgil@iq.uson.mx

\section{Resumen}

Este artículo presenta la variación de la conductividad hidráulica saturada de arenas finas con el contenido de finos y con el grado de acomodo, en muestras remoldeadas. Las muestras de suelo se formaron con la humedad óptima y peso volumétrico seco correspondiente a la relación de vacíos del grado de acomodo de la arena fina. La conductividad hidráulica saturada se determinó con el método del permeámetro de carga constante y con el de carga variable. No hubo diferencias significativas entre ambos métodos de prueba.

Palabras clave: Conductividad hidráulica, permeámetro de carga constante, permeámetro de carga variable.

\begin{abstract}
In this paper, the hydraulic conductivity of fine sands with different fines content and relative density are reported under saturation conditions, in alterated samples. Each sample was prepared by mixing preespecified amounts of sand and silt in different proportions. The compacted samples were adjusted so that their optimum water content and dry volumetric weight provided the void ratio corresponding to that of single fine sand. The hydraulic conductivity of the samples was determined by both constant head and falling head apparatus. The hydraulic conductivity values were found to be independent of the measurement technique.
\end{abstract}

Keywords: Hydraulic conductivity, constant head permeameter, falling head permeameter.

1 Depto. de Ingeniería Civil y Minas, Universidad de Sonora / Correo: jaespinoza@dicym.uson.mx 


\section{INTRODUCCIÓN}

Los principales problemas en los que la conductividad hidráulica saturada de los suelos, es indispensable son: i) La velocidad a la que el agua fluye a través del suelo, ii) La consolidación del suelo para calcular la velocidad de asentamiento de una cimentación, y iii) La resistencia del suelo para calcular su factor de seguridad. Además, la conductividad hidráulica saturada juega un papel importante en los procesos de transporte y redistribución de solutos en suelos y acuíferos [1]. La conductividad hidráulica depende tanto de la microestructura (disposición de las partículas), como de la macroestructura (estratificación, grietas, etcétera), por lo cual es importante su determinación in situ; sin embargo, la determinación en laboratorio permite estudiar la relación entre la conductividad hidráulica con la relación de vacíos [2] o con el contenido de finos.

El flujo de agua en medios porosos está gobernado por una ley experimental descubierta por Henry Darcy en 1856, la cual para el caso de flujo unidimensional se expresa como sigue [2] [3]:

$$
q=\frac{Q}{A}=\frac{V}{A t} \approx \frac{\Delta H}{L} ; \frac{V}{A t}=k_{s} \frac{\Delta H}{L}
$$

donde: $q$ es la velocidad de flujo, $Q$ es el gasto que pasa a través de la masa de suelo, $A$ es el área de la sección transversal perpendicular a la dirección del flujo, $\mathrm{V}$ es el volumen de agua que pasa por la masa de suelo, $t$ es el tiempo en que pasa el volumen de agua; $\Delta \mathrm{H}$ es la diferencia de carga hidráulica total entre las fronteras de entrada y salida de agua, $L$ es la longitud de la masa de suelo; a la relación $\Delta \mathrm{H} / \mathrm{L}$ se le llama gradiente hidráulico, que es la fuerza motriz que induce el flujo y $\mathrm{k}_{\mathrm{s}}$ es el coeficiente de proporcionalidad designado generalmente como coeficiente de conductividad hidráulica.

La ley de Darcy se basa en las siguientes hipótesis: i)

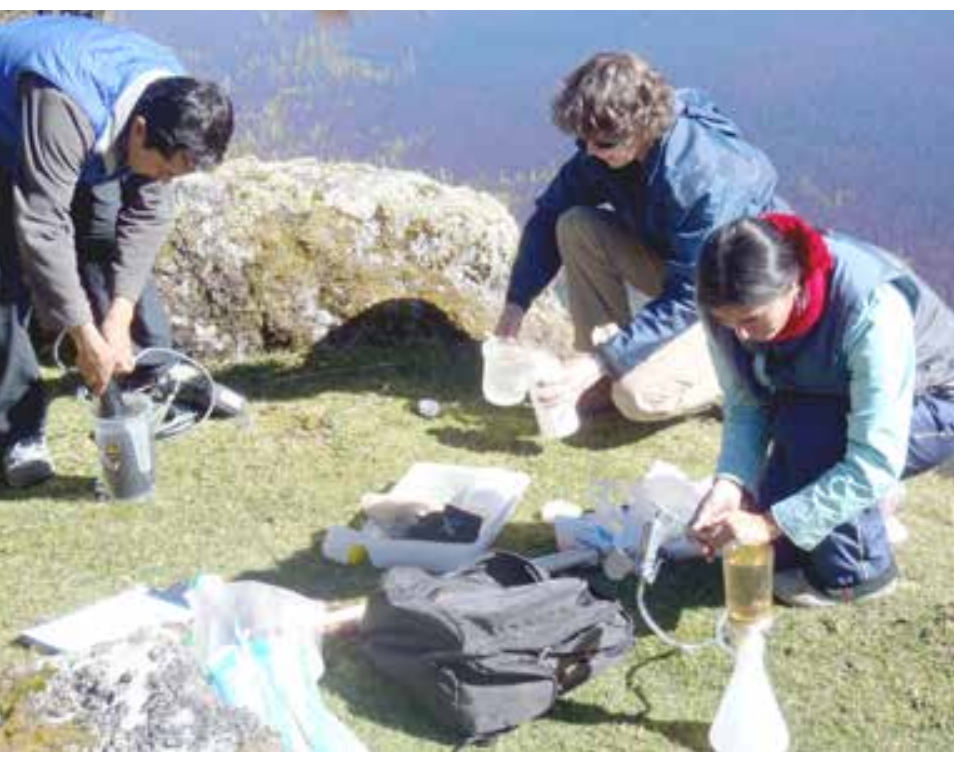

Las fuerzas inerciales son despreciables en comparación con las fuerzas viscosas, ii) El agua está conectada en toda la región de flujo, iii) Prevalecen condiciones isotérmicas, iv) No hay fenómenos químicos o biológicos que cambien al fluido o al medio poroso, v) La estructura del suelo no cambia con variaciones en su contenido de agua, y vi) El volumen del suelo es lo suficientemente grande con respecto al tamaño de los poros y heterogeneidades microscópicas para permitir promediar la velocidad y el potencial sobre la sección transversal expuesta al flujo [3].

La conductividad hidráulica de un suelo saturado depende principalmente de los siguientes factores: i) Tipo de suelo, ii) Relación de vacíos del suelo, y iii) Estructura (micro y macroestructura) [4].

\section{MATERIALES Y MÉTODOS}

\section{Métodos de prueba}

La determinación de la conductividad hidráulica saturada de los suelos se determina en el laboratorio con el permeámetro de carga constante y con el de carga variable [3] [4] [5]. El permeámetro de carga constante es adecuado para la mayoría de los suelos con $\mathrm{k}_{\mathrm{s}}>10^{-4} \mathrm{~m} \mathrm{~s}^{-1}$ y se aplica bajo un régimen de flujo permanente [6]. El método consiste en aplicar una diferencia de carga hidráulica total al suelo, la cual permanece constante durante la prueba. Cuando se alcanza el equilibrio hidráulico se mide el volumen de agua que pasa por la muestra en determinado tiempo. La conductividad hidráulica se determina con la siguiente ecuación:

$$
k_{s}=\frac{V L}{A t \Delta H}
$$

El permeámetro de carga variable se usa para determinar la conductividad hidráulica de los suelos bajo un régimen transitorio, y es apropiado para suelos de grano fino con $\mathrm{k}_{\mathrm{s}}<10^{-4} \mathrm{~m} \mathrm{~s}^{-1}$ [5]. El método consiste en hacer pasar un volumen de agua por la muestra de suelo, desde una carga hidráulica total inicial a una final medida a lo largo de un tubo que suministra el agua y registrando el tiempo en que pasa el agua desde la carga hidráulica inicial a la final. La conductividad hidráulica se calcula con la siguiente ecuación:

$$
k_{s}=\frac{L a}{A t} \ln \frac{h_{0}}{h_{f}}
$$

donde: $a$, es el área del tubo de suministro de agua; $h_{0}$, la carga hidráulica total al inicio de la prueba, $\mathrm{h}_{\mathrm{f}}$ la carga hidráulica total al final de la prueba (las demás variables ya se definieron).

Para la realización del presente trabajo se diseñó un permeámetro que permite utilizar los dos métodos de prueba, usando la misma muestra de suelo. El permeámetro consta de un contenedor con un pequeño vertedor para facilitar el desagüe del agua que atraviesa a la muestra, 


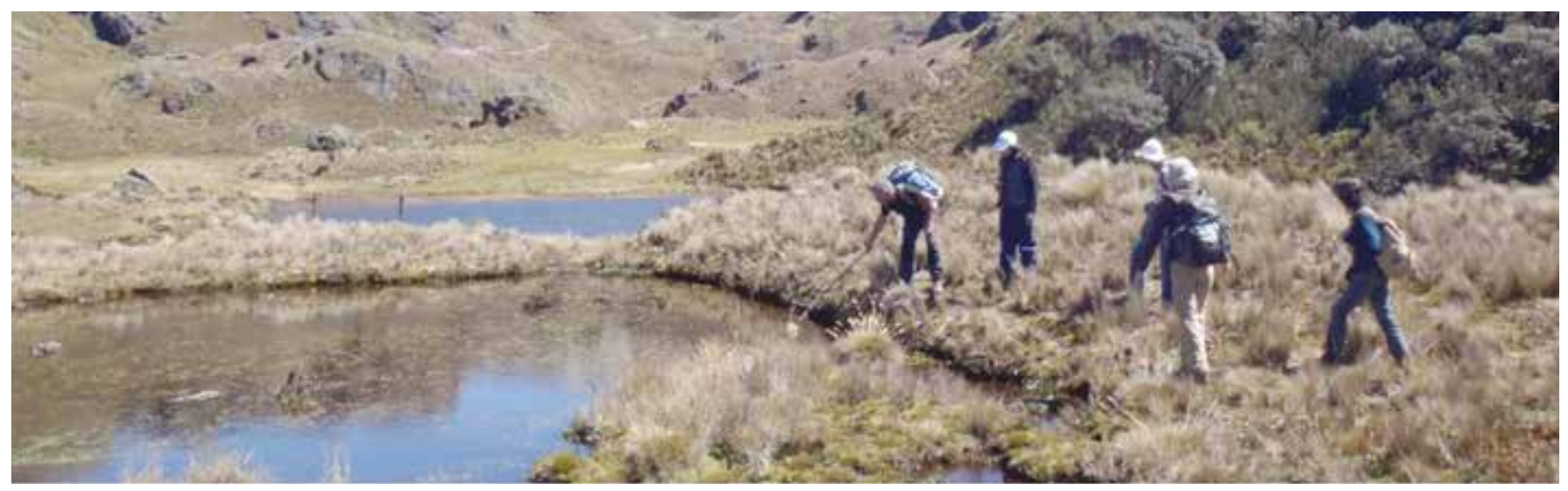

en donde se coloca un tubo cilíndrico de acrílico de 7.0 $\mathrm{cm}$ de diámetro y $18.0 \mathrm{~cm}$ de longitud que contiene a la muestra de suelo; este tubo se une herméticamente a una base de plástico con pequeñas perforaciones concéntricas $y$, en su parte superior se ajusta a otra placa de plástico, uniéndose ambas, junto con el permeámetro, por medio de cuatro tornillos de acero inoxidable. En la placa superior se conecta un tubo de vidrio para medir la carga hidráulica, así como el sistema de abastecimiento de agua controlado con una válvula.

Para determinar la conductividad hidráulica con el permeámetro de carga constante, se mantiene la válvula del sistema de suministro de agua abierta durante todo el tiempo de duración de la prueba. Para realizar la prueba con el método del permeámetro de carga variable, la válvula de suministro de agua se mantiene abierta sólo hasta que el nivel del agua en el tubo de vidrio alimentador alcanza la carga hidráulica total inicial entonces, la válvula se cierra y se mide el tiempo en que el agua desciende por el tubo hasta que pasa por la carga hidráulica total final.

La carga hidráulica se midió con una precisión de \pm 0.5 $\mathrm{mm}$, se usó una balanza (modelo PM 4000, marca Mettler, Suiza) de $4.0 \mathrm{~kg}$ de capacidad y $0.1 \mathrm{~g}$ de precisión para medir la cantidad de agua infiltrada a través de la muestra. El diámetro y altura de la muestra se midieron con un vernier digital marca Mitutoyo de $30.0 \mathrm{~cm}$ de capacidad y $0.01 \mathrm{~mm}$ de precisión. Todas las pruebas se hicieron en un cuarto con temperatura controlada y se midió la temperatura del agua infiltrada con un termómetro de $50.0{ }^{\circ} \mathrm{C}$ y $0.1{ }^{\circ} \mathrm{C}$ de precisión.

\section{Preparación de mezclas y especímenes de prueba}

Para estudiar la variación de la conductividad hidráulica saturada de un suelo granular con el contenido de finos limosos y densidad relativa, se seleccionó una arena limpia de finos, color blanco, de grano fino y uniforme, procedente de San Carlos, Nuevo Guaymas, Sonora, y un limo color café claro de la ciudad de Hermosillo, Sonora.

La arena no contiene gravas, tiene $99.52 \%$ de arenas y $0.48 \%$ de finos, no presenta plasticidad, tiene un peso volumétrico seco máximo de $1,567 \mathrm{~kg} \mathrm{~m}^{-3}$ y una humedad óptima de $18.57 \%$, su peso volumétrico seco mínimo es de $1,418 \mathrm{~kg} \mathrm{~m}^{-3}$ y su gravedad específica de los sólidos, de 2.697; la arena se clasifica como una arena mal graduada (SP). El limo no contiene gravas, tiene $33.8 \%$ de arenas y $66.2 \%$ de finos, su límite líquido es de $24.2 \%$ y su límite plástico, de $18.5 \%$, tiene un peso volumétrico seco máximo de $1,860 \mathrm{~kg} \mathrm{~m}^{-3}$ y una humedad óptima de $14.2 \%$, su peso volumétrico seco mínimo es de $1,093 \mathrm{~kg} \mathrm{~m}^{-3}$ y su gravedad específica de los sólidos es de 2.711 , clasificado como un limo de baja compresibilidad (ML). Los suelos se clasificaron según el Sistema Unificado de Clasificación de Suelos (S.U.C.S.).

Ambos suelos se cribaron por separado por la malla no. $30(0.590 \mathrm{~mm})$, en el caso de la arena para retirar prácticamente la escasa materia orgánica (detectada visualmente) y en el caso del limo para separar los pequeños grumos de suelo formados; estos grumos se disgregaron con un mazo de madera de $1.0 \mathrm{~kg}$ de peso y luego se cribaron de nuevo por la malla no. 30 . Posteriormente, ambos suelos se secaron al aire durante 36 horas, a continuación se homogeneizaron y se guardaron en recipientes con tapa hermética para la formación de las mezclas.

Se formaron mezclas de $30.0 \mathrm{~kg}$ secos de cada mezcla (para esto se determinó previamente el contenido de agua de la arena y del limo) porque además de realizar las pruebas de conductividad hidráulica, se tenían que determinar sus propiedades índice. La cantidad en peso de limo por añadir a la arena, se determinó en porcentaje con respecto al peso seco total de cada mezcla. Las mezclas se formaron con los siguientes porcentajes de limo de baja compresibilidad: $4,8,12,16,20,24,32,40,48,64$ y $88 \%$ y se designaron con dicho porcentaje; a la arena y al limo se les designó como 0 y $100 \%$ respectivamente.

Todas las mezclas se homogeneizaron y se guardaron en recipientes con tapa hermética. Los ensayes de laboratorio que se realizaron a cada mezcla fueron los siguientes: i) Análisis granulométrico, ii) Límites de consistencia (límite líquido y límite plástico), iii) Gravedad específica de los sólidos, iv) Peso volumétrico seco máximo y humedad óptima (Próctor estándar), y v) Peso volumétrico seco mínimo. Las propiedades índices de cada mezcla se presentan en la tabla 1. 


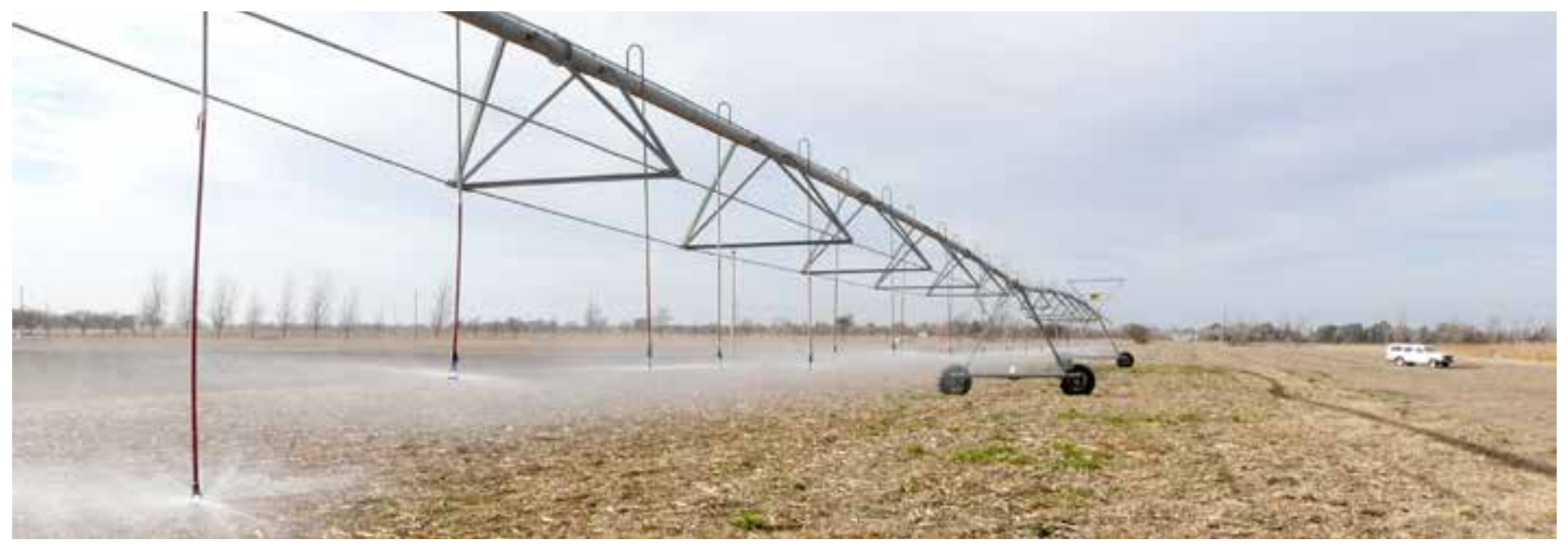

donde: $W_{s}$ es el peso volumétrico húmedo y $\mathbf{W}_{\text {opt. }}$ la humedad óptima de cada mezcla.

El suelo se coloca en el cilindro de acrílico en cuatro capas de igual peso, compactando cada una con un pisón metálico de $2.0 \mathrm{~kg}$ de peso, con el cual se aplicó la energía de compactación de la prueba Proctor estándar (espécimen); cada capa se escarificó previamente a la colocación de la siguiente para lograr una liga adecuada entre ellas, esto mismo se hizo con la última capa para evitar que la superficie lisa de ésta afectara al proceso de infiltración del agua.

\section{Verificación de la Ley de Darcy}

Con un espécimen formado con la mezcla de $4.0 \%$, la cual contenía $3.12 \%$ de finos y con una compacidad relativa de $25.0 \%$, se verificó experimentalmente la Ley de Darcy. El peso volumétrico seco de la muestra fue 1,453.6 $\mathrm{kg} / \mathrm{m}^{-3}$, tenía un diámetro de $7.0 \mathrm{~cm}$, una altura de $14.0 \mathrm{~cm}$ y un contenido de agua igual a $15.02 \%$.

El espécimen se saturó por su parte inferior usando agua destilada, para esto se incrementó gradualmente el nivel del agua a razón de $2.0 \mathrm{~cm}$ cada $3 \mathrm{~h}$; durante este proceso se agregó al agua un inhibidor biológico en proporción de 6 gotas por litro (Bussan ${ }^{\circledR}$, laboratorio Buckman, Cuernavaca, Morelos); luego se colocó el espécimen en el contenedor con vertedor y se ajustó el sistema alimentador de agua para aplicar la diferencia de carga hidráulica $(\Delta \mathrm{H})$, teniendo especial cuidado de extraer todas las burbujas de aire atrapadas entre la parte superior del especimen y la placa de plástico superior.

Se aplicó una diferencia de carga hidráulica al especimen y se midió la cantidad de agua infiltrada y el tiempo respectivo para obtener el gasto. Se varió la diferencia de carga hidráulica en cinco ocasiones y en cada una se hicieron cinco determinaciones para obtener un valor promedio del gasto de agua infiltrado. Todas las mediciones se hicieron en un laboratorio con ambiente de temperatura controlado; la temperatura varió de 20.1 a $20.4{ }^{\circ} \mathrm{C}$. Los resultados se muestran en la figura 1 , de donde se concluye que la Ley de Darcy se cumple dentro del rango de gradiente hidráulico probado $(0.34 \leq \Delta \mathrm{H} / \Delta \mathrm{L}$ $\leq 1.10)$.

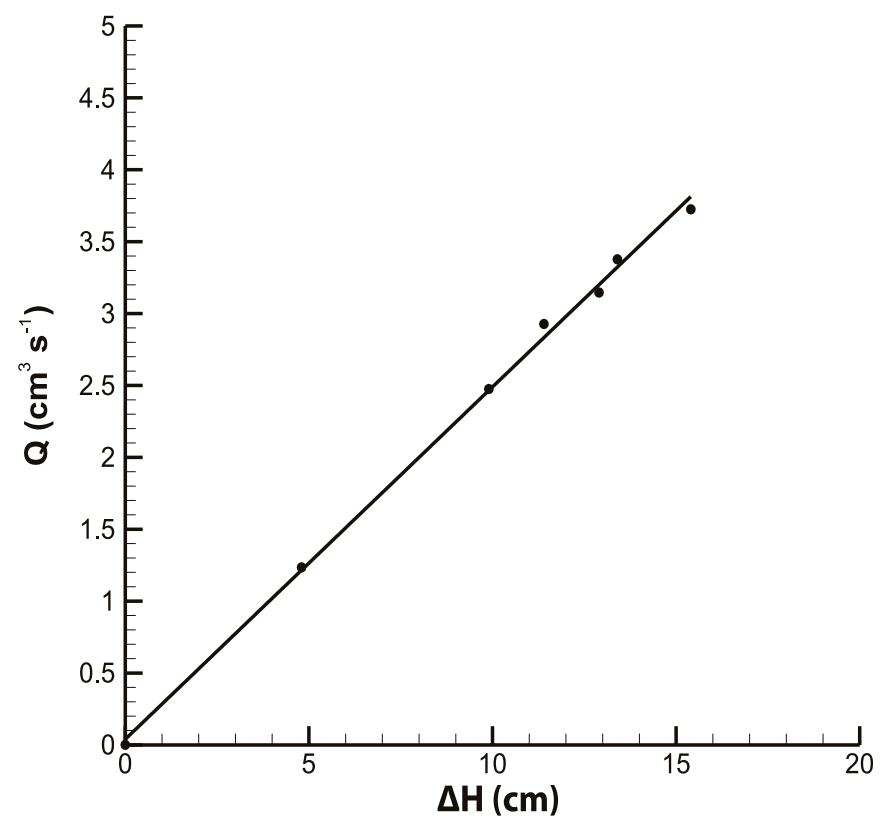

Figura 1. Verificación de la Ley de Darcy.

\section{Medición de la conductividad hidráulica saturada}

A cada uno de los especímenes formados con compacidades relativas de $25,50,75$ y $100 \%$ de cada mezcla, se les determinó la conductividad hidráulica saturada con el método del permeámetro de carga constante y con el de carga variable. Todas las pruebas se realizaron en un laboratorio climatizado; sin embargo, debido a la cantidad de pruebas realizadas, las cuales se llevaron a cabo en varios días, la temperatura varió de 18.8 a $25.2^{\circ} \mathrm{C}$; durante el proceso de saturación se utilizó agua destilada y un inhibidor biológico.

Primeramente se determinó la conductividad hidráulica con el permeámetro de carga hidráulica constante, para esto se ajustó el sistema de suministro de agua cuidadosamente, a una altura tal que el gradiente hidráulico aplicado fuera menor que la unidad, manteniendo siempre la válvula del sistema de suministro de agua abierta para mantener la carga hidráulica constante. Previamente a la realización de las pruebas, se 


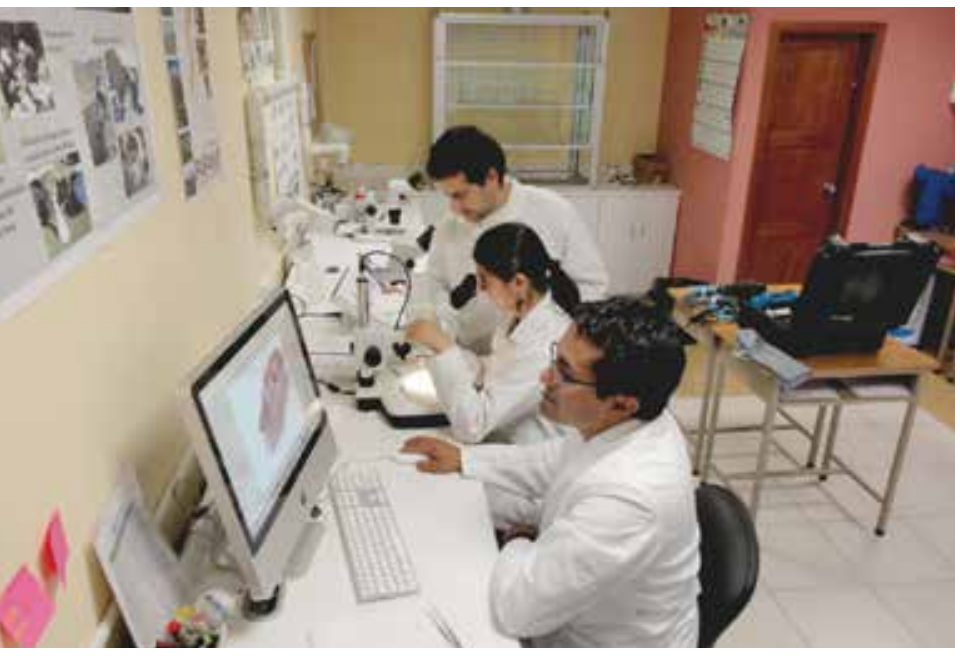

infiltró a través de cada especimen una cantidad de agua durante un tiempo de 10 a 50 minutos para garantizar la condición de flujo establecido, la variación del tiempo se debió al efecto del grado de acomodo y al contenido de finos de los especímenes. A cada especimen se le hicieron cinco determinaciones, variando el tiempo de infiltración de agua, para obtener una conductividad hidráulica promedio. Debido a que en este trabajo se midió el peso de agua infiltrada a través de la muestra, el volumen que aparece en la Ec. (1) se obtuvo en función del peso de agua y el peso volumétrico del agua, por lo que la Ec. (2) queda de la siguiente forma:

$$
K_{s}=\frac{W L}{\gamma_{\omega} A t \Delta H}
$$

dónde: $W$ es la cantidad de agua infiltrada, $\gamma_{\omega}$ es el peso volumétrico del agua a la temperatura de prueba; las demás variables ya fueron definidas.

Una vez realizadas las pruebas con el permeámetro de carga constante, se procedió a medir la conductividad hidráulica de los mismos especímenes con el método del permeámetro de carga variable, para esto se elevó ligeramente el sistema de suministro de agua, se cerró la válvula del sistema (para que la carga hidráulica disminuyera) y al momento en que la columna de agua pasó por la marca de la carga hidráulica inicial, se accionó el cronómetro para medir el tiempo que tardó la columna de agua en llegar a la marca de la carga hidráulica final, momento en el cual se registró el peso de agua infiltrado y su temperatura. Debido a la rapidez con que se infiltró el agua en la mayoría de los especímenes de las mezclas de suelo, se hicieron diez determinaciones para obtener un promedio de la conductividad hidráulica.

\section{RESULTADOS Y DISCUSIÓN}

Los resultados de la conductividad hidráulica saturada obtenidos con el método de carga variable y carga constante, se muestran en las figuras 2 y 3 , respectivamente.

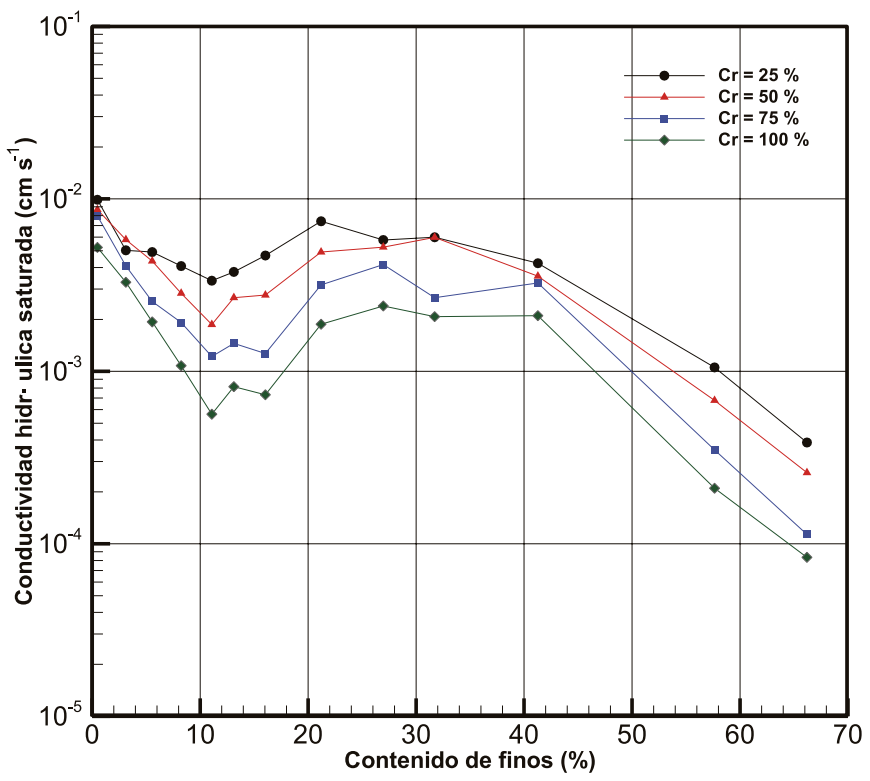

Figura 2. Variación de $K_{s}$ con el contenido de finos y la compacidad relativa, permeámetro de carga constante.

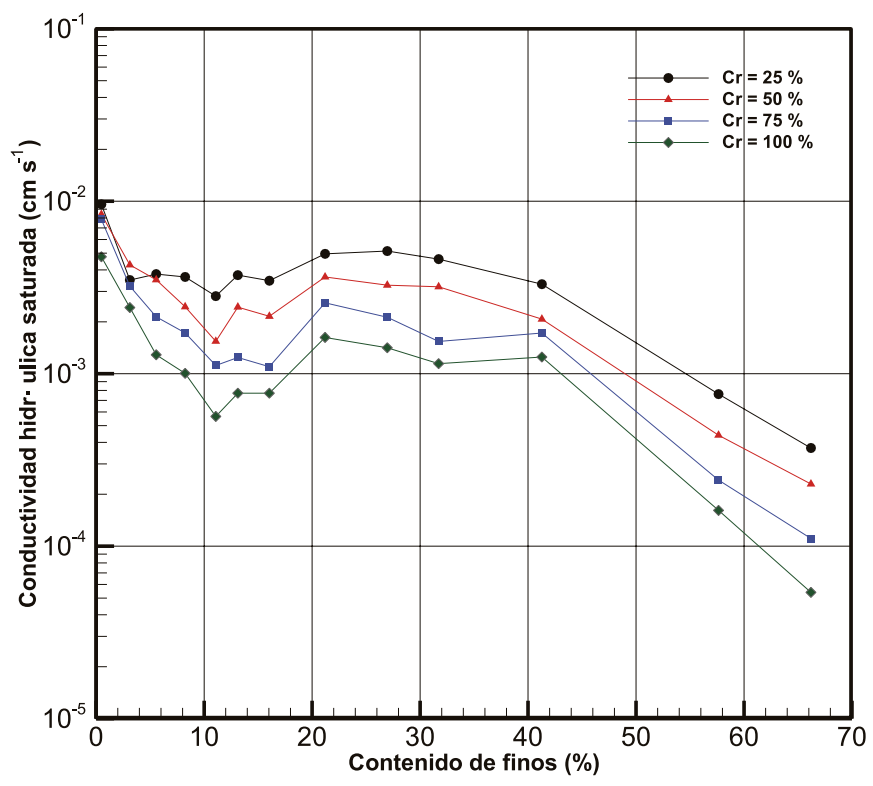

Figura 3. Variación de $K_{s}$ con el contenido de finos y la compacidad relativa, permeámetro de carga variable.

La conductividad hidráulica saturada disminuyó al aumentar la compacidad relativa para el mismo contenido de finos en todas las muestras de suelo. Los valores de $K_{s}$ obtenidos con el método de carga constante fueron ligeramente mayores que los obtenidos con el método de carga variable. La variación de $K_{s}$ con el contenido de finos y compacidad relativa, presentó el mismo patrón de comportamiento con ambos métodos de prueba.

El valor de $K_{s}$ disminuyó al incrementarse el contenido de finos de 0.48 a $11.08 \%$ para todas las compacidades 
relativas, sólo en los especímenes con compacidad relativa de $100 \%$ la disminución fue de un orden de magnitud $\left(10^{-3} \mathrm{a} 10^{-4} \mathrm{~cm} \mathrm{~s}^{-1}\right)$. Al incrementar el contenido de finos de 11.08 a $16.04 \%$, la conductividad hidráulica aumentó ligeramente en todos los casos y ese incremento fue mayor cuando el contenido de finos fue de $21.20 \%$. Cuando el contenido de finos aumentó hasta $31.72 \%$, los valores de $K_{s}$ se mantuvieron prácticamente constantes dentro del orden de magnitud de $10^{-3} \mathrm{~cm} \mathrm{~s}^{-1}$; disminuyó ligeramente para los especímenes con $41.28 \%$ de finos, pero en el mismo orden de magnitud.

Las muestras con contenido de finos igual a $57.64 \%$ disminuyeron el valor de $K_{s}$ en un orden de magnitud de

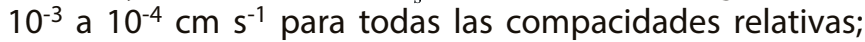
en las muestras con contenido de finos igual a $66.20 \%$, los valores de $K_{s}$ disminuyeron manteniéndose dentro del orden de de $10^{-4} \mathrm{~cm} \mathrm{~s}^{-1}$ y sólo en las muestras con compacidad relativa de $100 \%$ el valor de $K_{s}$ disminuyó hasta el orden de magnitud de $10^{-5} \mathrm{~cm} \mathrm{~s}^{-1}$.

Influencia de la relación de vacíos. Una de las causas que podrían explicar la variación de $K_{s}$ con el contenido de finos, es que las muestras no se hayan formado adecuadamente con la relación de vacíos deseada; en la figura 4 se presenta la variación de la relación de vacíos con el contenido de finos; en dicha gráfica se observa que la relación de vacíos es prácticamente constante para cada compacidad relativa, y por lo tanto, no explica la variación de $K_{s}$.

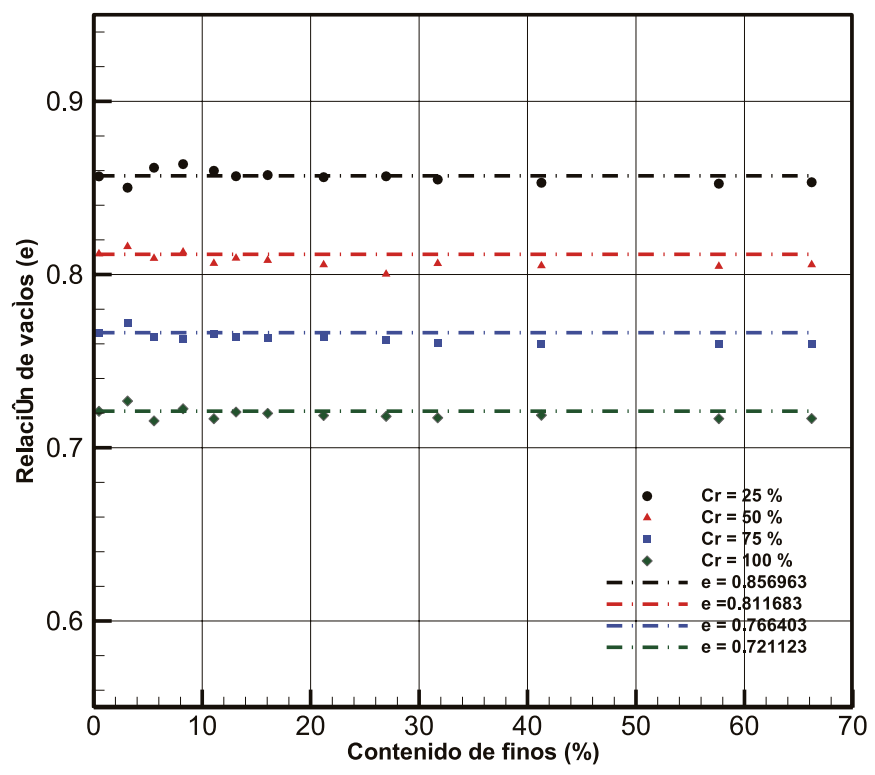

Figura 4. Variación de la relación de vacíos de las muestras con el contenido de finos y la compacidad relativa.

Influencia de la temperatura. Se considera comúnmente que el efecto de la temperatura sobre $K_{s}$ se debe principalmente a cambios en la viscosidad del agua, debido a que existe una relación de proporcionalidad entre $K_{s}$ y ésta [3]; bajo esta suposición, el cambio de temperatura del agua infiltrada entre pruebas realizadas en mezclas consecutivas $\left(18.8\right.$ a $25.2^{\circ} \mathrm{C}$ ) no es suficiente para explicar las variaciones en el valor de $K_{s}$.

Arrastre de finos. El arrastre de partículas finas por efecto del flujo de agua, también se consideró como una de las posibles causas de la variación de $K_{s}$; sin embargo, no se observó turbiedad en el agua que indicara la salida de partículas finas de la muestra, aún cuando el gradiente hidráulico se aumentó para realizar las pruebas con el método de carga variable (la variación de $K_{s}$ fue la misma con ambos métodos de prueba), por lo que esta causa se descarta.

Crecimiento de bacterias. El crecimiento de bacterias puede ocasionar una reducción importante de $K_{s}$ con el tiempo, ya que pueden obstruir los poros del suelo [7]. En nuestro caso, esta hipótesis puede descartarse debido a que durante todo el proceso de saturación se usó un inhibidor biológico; además las pruebas se hicieron con agua destilada y las mediciones duraron cuando mucho tres horas.

\section{CONCLUSIONES}

Se pudo realizar la caracterización hidrodinámica de una arena limpia a la cual se le añadieron distintos porcentajes de finos limosos, para cuatro compacidades relativas diferentes $(25,50,75$ y $100 \%)$, usando el método del permeámetro de carga constante, y el de carga variable.

El valor de $K_{s}$ disminuye al aumentar la compacidad relativa, independientemente del contenido de finos.

Los valores de $K_{s}$ obtenidos con el método del permeámetro de carga constante fueron ligeramente mayores a los obtenidos con el método del permeámetro de carga variable, para todas las compacidades relativas.

Se puede considerar que no hubo variación significativa en los valores de $K_{s}$ con el contenido de finos y la compacidad relativa, hasta que el contenido de finos fue superior a $41.28 \%$.

\section{BIBLIOGRAFÍA}

[1] L. Gao, M. Shao y Y. Wang. "Spatial scaling of saturated hydraulic conductivity of soils in a small watershed on the loess plateau, China". Soils Sediments Journal 12: pp. 863875. 2012

[2] T. Lambe y R. Whitman R. "Mecánica de suelos". LIMUSA (ed), México, D.F. 582 p. 2010.

[3] D. Hillel. "Fundamentals of soil physics". Academic press (ed), London (UK). 413 p. 1980.

[4] B. Juárez y R. Rico. "Mecánica de suelos I". LIMUSA (ed), México, D.F. 642 p. 1989.

[5] G. Spangler y R. Handy. "Soil Engineering". Harper \& Row Publishers (ed). New York (USA). 819 p. 1982.

[6] D. Daniel, D. "Hydraulic conductivity and waste contaminant in soil". American Society for Testing and Materials (ASTM) 1142: pp. 16-42. 1994.

[7] P. Vandevivere y P. Baveye. "Saturated hydraulic conductivity reduction caused by aerobic bacteria in sand columns". Soil Science American Journal. 56 p. 1992. 